\title{
DESKRIPSI SISTEM ANTRIAN PADA KLINIK DOKTER SPESIALIS PENYAKIT DALAM
}

\author{
Deiby T. Salaki ${ }^{1)}$ \\ ${ }^{1)}$ Program Studi Matematika FMIPA Universitas Sam Ratulangi \\ Jl. Kampus Unsrat Manado, 95115 \\ e-mail: deibytineke@yahoo.co.id
}

\begin{abstract}
ABSTRAK
Penelitian ini dilakukan untuk mengetahui deskripsi sistem antrian pada klinik dokter internist. Pengumpulan data dilakukan secara langsung pada klinik dokter internist JHA selama 12 hari, selama 2 jam waktu pengamatan tiap harinya pada periode sibuk.. Model antrian yang digunakan adalah model (M/M/1) : (FIFO/ / ), tingkat kedatangan bersebaran poisson, waktu pelayanan bersebaran eksponensial, dengan jumlah pelayanan adalah seorang dokter, disiplin antrian yang digunakan adalah pasien yang pertama datang yang pertama dilayani, jumlah pelayanan dalam sistem dan ukuran populasi pada sumber masukan adalah tak berhingga. Sistem antrian pada klinik ini memiliki kecepatan kedatangan pelayanan anamnesa rata-rata 3,256 menit 1 orang pasien datang, kecepatan kedatangan pelayanan pemeriksaan fisik rata-rata 3,255 menit 1 orang pasien datang, rata-rata waktu pelayanan anamnesa untuk seorang pasien 2,675 menit, rata-rata waktu pelayanan pemeriksaan fisik untuk seorang pasien 12,635 menit, peluang kesibukan pelayanan anamnesa sebesar 0,864 , peluang kesibukan pelayanan pemeriksaan fisik sebesar 0,832 , dan peluang pelayanan anamnesa menganggur sebesar 0,136 , peluang pelayanan pemeriksaan fisik menganggur sebesar 0,168. Rata-rata banyaknya pengantri untuk anamnesa adalah 5,485 pasien sedangkan untuk pemeriksaan fisik 4,119 pasien, rata-rata banyaknya pengantri dalam sistem adalah 9,604 pasien, waktu rata-rata seorang pasien dalam klinik adalah 47,078 menit, waktu rata-rata seseorang pasien untuk antri adalah 31,660 menit.
\end{abstract}

Kata kunci: Sistem Antrian, Klinik Penyakit Dalam

\section{DESCRIPTION OF QUEUING SYSTEM AT THE INTERNIST CLINIC}

\begin{abstract}
This research determines the description of queuing system at the internist Clinic. Data collected by direct observation during 12 days and in 2 hours. Queuing model that used is model of (M/M/1): (FIFO / / ). Based on the research, the clinic has 3.256 minutes per patient in average arrival rate for anamnesys, the average arrival rate for diaagnosys is 3.255 minutes per patient, average service speed for anamnesys is 2.675 minutes per patient, average service speed for diagnosys is 12.635 minutes, the probability of busy periods for anamnesys is 0.864 , the probability of busy periods for diagnosys is 0.832 and probability of all free services or no patient in the anamnesys equal to 0.136 , probability of all free services or no patient in the anamnesys equal to 0.168 . The average number of patients in anamnesys queue is 5 patients, the average number of patients in diagnosys queue is 4 patients, the average number of patients in the system is 10 patients, the average waiting time in the system is 47.078 minutes and the average queuing time is 31.660 minutes.
\end{abstract}

Keywords: Queuing system, internist clinic

\section{PENDAHULUAN}

Antrian timbul karena jumlah fasilitas pelayanan jasa lebih sedikit dibandingkan dengan jumlah orang yang memerlukan pelayanan bersangkutan (Susetyo, 2009). Dalam model-model antrian, kedatangan pelanggan dan waktu pelayanan dijelaskan 
dalam bentuk sebaran peluang, yang umumnya disebut sebagai sebaran kedatangan dan sebaran waktu pelayanan. Selain kedua faktor tersebut ada faktor lain yang juga cukup penting dalam pengembangan model-model antrian, seperti: rancangan sarana pelayanan, peraturan pelayanan dan prioritas pelayanan, ukuran antrian, dan perilaku manusia menjadi hal yang tidak tidak terlepas dari masalah antrian ini.

Dunia kesehatan juga tak luput dari kegiatan mengantri misalnya antrian pelayanan di klinik dokter atau fasilitas pelayanan kesehatan lainnya.

Penelitian ini ditujukan untuk menentukan sistim antrian pada salah satu klinik dokter spesialis penyakit dalam yaitu klinik dr. JHA di Manado. Pengambilan data dilakukan selama 12 hari masing-masing selama 2 jam pengamatan pada periode sibuk dengan model antrian tunggal banyak tahapan pelayanan.

\section{TINJAUAN PUSTAKA}

\section{Teori Antrian}

Teori Antrian (queuing theory) merupakan studi matematika dari antrian atau kejadian garis tunggu dari pelanggan yang memerlukan layanan dari sistem yang ada (Kakiay, 2004). Sebuah organisasi harus berusaha memberikan pelayanan agar pelanggan tidak mengantri terlalu lama. Biasanya ada biaya bagi organisasi untuk menambah fasilitas layanan.

Layanan yang cepat akan mempertahankan pelanggan dan jangka panjang meningkatkan keuntungan perusahaan.

Sebuah sistem antrian adalah suatu himpunan pelanggan, pelayan dan suatu antrian yang mengatur kedatangan pelanggan dan pemrosesan masalahnya. Pelanggan yang tiba dapat bersifat tetap atau tidak tetap untuk memperoleh pelayanan. Apabila pelanggan yang tiba dapat langsung masuk kedalam sistem pelayanan maka pelanggan tersebut langsung dilayani, sebaliknya jika harus menunggu maka mereka harus membentuk antrian hingga tiba waktu pelayanan (Hilier, 2008).

Disiplin antrian adalah aturan dimana para pelanggan dilayani. Aturan pelayanan menurut urutan kedatangan dapat didasarkan pada:

1. Pertama Masuk Pertama Keluar atau First In First Out (FIFO),

2. Yang Terakhir Masuk Yang Pertama Keluar atau Last In First Out (LIFO),

3. Pelayanan Dalam Urutan Acak atau Service In Random Order (SIRO),

4. Pelayanan Berdasarkan Prioritas (Pri) (Hilier, 2008).

Elemen-elemen dasar model antrian bergantung pada faktor sebaran kedatangan, barisan antri, mekanisme pelayanan, waktu pelayanan, dan sumber pelayanan (Taha, 1996).

\section{Model-Model Antrian.}

Ada empat model struktur antrian dasar yang umum terjadi dalam seluruh sistem antrian:

1. Satu Jalur, Satu Tahap (Single Channel, Single Phase)

2. Satu Jalur, Banyak Tahap (Single Channel, Multi Phase)

3. Banyak Jalur, Satu Tahap (Multi Channel, Single Phase)

4. Banyak Jalur, Banyak Tahap (Multi Channel, Multi Phase) (Bronson, 1998).

\section{Pola Kedatangan dan Lama Pelayanan}

Fungsi peluang poisson digunakan untuk menggambarkan tingkat kedatangan dengan asumsi bahwa jumlah kedatangan adalah acak dan kedatangan pelanggan antar interval waktu saling tidak mempengaruhi. Peluang tepat terjadinya $x$ kedatangan dalam sebaran poisson dapat diketahui dengan menggunakan rumus:

$$
P(x)=\frac{\lambda^{x} e^{-\lambda}}{x !}
$$

Sedangkan lama pelayanan mengikuti sebaran Eksponensial. Ini bisa dilakukan dengan membandingkan sampel waktu pelayanan yang sebenarnya dengan waktu pelayanan yang diharapkan berdasarkan rumus sebagai berikut:

(Mulyono, 2007).

$$
f(t)=\mu e^{-\mu t}
$$

\section{Model-model antrian Poisson}

1. $(\mathrm{M} / \mathrm{M} / 1):(\mathrm{GD} / \sim / \sim)$

2. $(\mathrm{M} / \mathrm{M} / 1):(\mathrm{GD} / \mathrm{N} / \sim)$

3. $(\mathrm{M} / \mathrm{M} / \mathrm{c}):(\mathrm{GD} / \sim / \sim)$

4. $(\mathrm{M} / \mathrm{M} / \mathrm{c}):(\mathrm{GD} / \mathrm{N} / \sim), \mathrm{c} \leq \mathrm{N}$

5. (M/M/ ) : (GD/ / ) Model Swalayan 
6. $(\mathrm{M} / \mathrm{M} / \mathrm{R})$ : $(\mathrm{GD} / \mathrm{K} / \mathrm{K}), \mathrm{R}<\mathrm{K}$ Model Perbaikan Mesin

\section{METODOLOGI PENELITIAN}

\section{Data Penelitian}

Data yang digunakan dalam penelitian ini merupakan data primer yang diambil secara langsung pada sistem antrian yang ada pada klinik dr. JHA. Waktu pengambilan data dilaksanakan selama 12 hari pada tanggal 6-18 Desember 2010, pada periode sibuk yaitu pada pukul $19.00-21.00$ WITA.

Sistem antrian pada klinik dr. JHA dapat dilihat pada Lampiran 1.

\section{Pengolahan Data}

\section{Uji Kesesuaian Eksponensial}

Untuk menghitung nilai $X_{1}$ dari data pengamatan pada $h_{1}, h_{2}$, sampai $h_{12}$, dihitung dengan menggunakan nilai waktu pelayanan yang diharapkan dengan menggunakan rumus sebaran Eksponensial, dengan hipotesis:

$H_{1}$ : Waktu pelayanan mengikuti sebaran Eksponensial

$H_{0}$ : Waktu pelayanan tidak mengikuti

\section{Uji Kesesuaian Poisson}

Untuk menghitung nilai $\chi^{2}$ dari data pengamatan pada $h_{1}, h_{2}$, sampai $h_{12}$, dihitung dengan menggunakan nilai tingkat kedatangan, dengan hipotesis:

$H_{1}$ :Kedatangan mengikuti sebaran Poisson $H_{0}$ : Kedatangan tidak mengikuti sebaran Poisson

Untuk menentukan nilai $\chi^{2}$ maka digunakan rumus:

$$
\chi^{2}=\sum_{i=1}^{k} \frac{\left(\lambda_{i}-\bar{\lambda}\right)^{2}}{\bar{\lambda}}
$$

Kriteria keputusan dilakukan dengan tolak $H_{0}$ apabila $\chi^{2}{ }_{\text {hitung }} \leq \chi^{2}$ tabel .

\section{Uji Kesesuaian Eksponensial}

Untuk menghitung nilai $X_{1}$ dari data pengamatan pada $h_{1}, h_{2}$, sampai $h_{12}$, dihitung dengan menggunakan nilai waktu pelayanan yang diharapkan dengan menggunakan rumus sebaran Eksponensial, dengan hipotesis:
$H_{1}$ : Waktu pelayanan mengikuti sebaran Eksponensial

$H_{0}$ : Waktu pelayanan tidak mengikuti sebaran Eksponensial

Untuk menentukan nilai $\chi^{2}$ maka digunakan rumus:

$$
\chi^{2}=\sum_{i=1}^{k} \frac{\left(\mu_{i}-\mu_{i \text { harapan }}\right)^{2}}{\mu_{i} \text { harapan }}
$$

Kriteria keputusan dilakukan dengan tolak $H_{0}$ apabila $\chi^{2}{ }_{\text {hitung }} \leq \chi^{2}{ }_{\text {tabel }}$ (Bronson, 1988).

Dalam melakukan perhitungan, penulis mengambil acuan dengan formula yang digunakan dalam pemecahan persoalan yang ditemukan di klinik, yaitu:

- Menentukan jumlah peluang masa sibuk $(\rho)$

$$
\rho=\frac{\lambda}{\mu}
$$

- Menentukan Peluang Semua Pelayanan Menganggur $\left(P_{0}\right)$

$$
P_{0}=1-\rho
$$

- Nilai rata-rata banyaknya pengantri dalam antrian $\left(L_{q}\right)$

$$
L_{q}=\frac{\rho^{2}}{1-\rho}
$$

- Nilai rata-rata banyaknya pengantri dalam sistem (L)

$$
L=\sum_{i=1}^{k} L_{q(i)}
$$

- Waktu Rata-rata yang Dihabiskan Seorang Pasien dalam Sistem $(W)$

$$
W=\frac{L}{\lambda}
$$

- Waktu Rata-rata yang Dihabiskan Seorang dalam Pasien Antrian $\left(W_{q}\right)$

$$
W_{q}=W-\mu
$$

\section{HASIL DAN PEMBAHASAN}

Dari hasil pengumpulan data, jumlah kedatangan pasien per hari per 15 menit selama waktu pengamatan. Berdasarkan rangkuman data, diketahui bahwa jumlah kedatangan pasien berkisar antara 23 sampai 33 pasien per hari. Jumlah kedatangan pasien yang paling sedikit terdapat pada hari ke-5 pengamatan, dan jumlah kedatangan pasien terbanyak terdapat pada hari ke-1 pengamatan. 
Rata-rata waktu pelayanan $\left(\frac{1}{\mu}\right)$ terhadap pasien per hari per 15 menit selama waktu pengamatan.

Pengujian Kesesuaian Poisson digunakan sebaran chi-square melalui tes goodness of fit. Dalam hal dilakukan uji kesesuaian poisson terhadap kedatangan dengan interval waktu 15 menit setiap harinya selama waktu pengamatan dan diperoleh

$$
\chi_{(1-\alpha)(k-1)}^{2}=\chi_{0,95(7)}^{2}=14,067
$$

Sehingga, $\quad \chi^{2}$ hitung $\leq \chi^{2}$ tabel yakni $2 \leq 14,067$, tolak $H_{0}$.

Maka diterima asumsi bahwa pola kedatangan pasien pada hari ke-1 untuk pelayanan anamnesa mengikuti sebaran Poisson.

Pada ingkat kedatangan pelayanan pemeriksaan fisik diperoleh $\chi_{(1-\alpha)(k-1)}^{2}=$ $\chi_{0,95(7)}^{2}=14,067$

Sehingga, $\quad \chi^{2}$ hitung $\leq \chi^{2}$ tabel yakni $1,182 \leq 14,067$, tolak $H_{0}$.

Maka diterima asumsi bahwa pola kedatangan pasien pada hari ke-1 untuk pelayanan pemeriksaan fisik mengikuti sebaran Poisson.

Uji kesesuaian pada waktu pelayanan pasien digunakan sebaran chi-square melalui tes goodness of fit, terlebih dahulu ditentukan nilai waktu pelayanan yang diharapkan $(\mu$ harapan $)$ dengan menggunakan rumus sebaran Eksponensial dan menggunakan nilai $t=0,25$ (jam) dan diperoleh $\quad \chi_{(1-\alpha)(k-1)}^{2}=\chi_{0,95(7)}^{2}=$ 14,067

Sehingga, $\quad \chi^{2}$ hitung $\leq \chi^{2}$ tabel yakni $0,512 \leq 14,067$, tolak $H_{0}$.

Maka diterima asumsi bahwa waktu pelayanan pasien untuk pelayanan anamnesa pada hari ke-1 mengikuti sebaran Eksponensial.

Demikian juga dengan waktu pelayanan fisik diperoleh

$\chi_{(1-\alpha)(k-1)}^{2}=\chi_{0,95(7)}^{2}=14,067$

Sehingga, $\quad \chi^{2}$ hitung $\leq \chi^{2}$ tabel yakni $1,116 \leq 14,067$, tolak $H_{0}$.

Maka diterima asumsi bahwa waktu pelayanan pasien untuk pelayanan pemeriksaan fisik pada hari ke-1 mengikuti sebaran Eksponensial.

Berdasarkan analisis terhadap tingkat kedatangan, waktu pelayanan, model antrian di Klinik dr. JHA adalah:
Kedatangan pelayanan anamnesa

$\lambda_{\text {anamnesa }}=\frac{3,667}{12}=0,306$ pasien per menit, atau selama 3,256 menit rata-rata 1 orang pasien datang.

Kedatangan pelayanan pemeriksaan fisik $\lambda_{\text {pemeriksaan fisik }}=\frac{3,635}{12}=0,303$ pasien per menit, atau selama 3,255 menit rata-rata 1 orang pasien datang.

Kecepatan pelayanan rata-rata anamnesa $\mu_{\text {anamnesa }}=\frac{4,248}{12}=0,354$ pasien per menit atau 1 pasien rata-rata dilayani dengan waktu 2,765 menit.

Kecepatan pelayanan rata-rata anamnesa

$\mu_{\text {pemeriksaan fisik }}=\frac{0,948}{12}=0,079$ pasien per menit atau 1 pasien rata-rata dilayani dengan waktu 12,653 menit.

Peluang masa sibuk pelayanan anamnesa

$\rho_{\text {anamnesa }}=\frac{0,306}{0,354}=0,864$

Peluang masa sibuk pelayanan pemeriksaan fisik

$\rho_{\text {pemeriksaan fisik }}=\frac{0,303}{0,364}=0,832$

Peluang pelayanan anamnesa menganggur $P_{0}$ anamnesa $=1-0,864=0,136$

Peluang pelayanan pemeriksaan fisik menganggur

$P_{0}$ pemeriksaan fisik $=1-0,832=0,168$

Nilai rata-rata banyaknya pengantri dalam antrian

$L_{q_{\text {anamnesa }}}=\frac{(0,864)^{2}}{1-0,864}=5,485$ pasien

$L_{q_{\text {pemeriksaan fisik }}}=\frac{(0,832)^{2}}{1-0,832}=4,119$

pasien

Nilai rata-rata banyaknya pengantri dalam system, $L=9,604$ pasien.

Waktu rata-rata yang dihabiskan seorang pasien dalam sistem, $W=47,078$ menit

Waktu rata-rata yang dihabiskan seorang pasien dalam antrian adalah $W_{q}=31,660$ menit.

Model antrian yang digunakan pada klinik dr. JHA adalah model (M/M/1) : (FIFO/ / ).

\section{KESIMPULAN DAN SARAN}

\section{Kesimpulan}

Pada sistem antrian klinik dr. JHA, kecepatan kedatangan pelayanan anamnesa rata-rata 3,256 menit 1 orang pasien datang, kecepatan kedatangan pelayanan 
pemeriksaan fisik rata-rata 3,255 menit 1 orang pasien datang, rata-rata waktu pelayanan anamnesa untuk seorang pasien 2,675 menit, rata-rata waktu pelayanan anamnesa untuk seorang pasien 12,635 menit, peluang kesibukan pelayanan anamnesa sebesar 0,864, peluang kesibukan pelayanan anamnesa sebesar 0,832 , dan peluang pelayanan anamnesa menganggur sebesar 0,136, peluang pelayanan pemeriksaan fisik menganggur sebesar 0,168 . Rata-rata banyaknya pengantri dalam antrian anamnesa adalah 5 pasien, rata-rata banyaknya pengantri dalam antrian pemeriksaan fisik adalah 4 pasien, rata-rata banyaknya pengantri dalam sistem adalah 10 pasien, waktu rata-rata seorang pasien dalam klinik adalah 47,078 menit, waktu rata-rata seseorang pasien untuk antri adalah 31,660 menit.

\section{Saran}

Sebaiknya tingkat kedatangan pasien dan pelayanan pasien selalu diamati, sehingga dapat ditentukan kebijakan untuk mengantisipasi antrian. Penelitian lanjutan dapat digunakan teknik simulasi terhadap sistem antrian ini.

\section{DAFTAR PUSTAKA}

Bronson, R dan Hans, J. 1988. Teori dan Soal-Soal Operation Research, seri buku Schaum's. Erlangga. Jakarta.

Hilier L. 2008. Introduction to Operations Research, jilid 2. Penerbit Andi. Yogyakarta.

Kakiay, T. J. 2004. Dasar Teori Antrian untuk Kehidupan Nyata. Penerbit Andi. Yogyakarta.

Mulyono, S. 2007. Riset Operasi. Lembaga Penerbit Fakultas Ekonomi-UI. Jakarta.

Taha, H. A. 1996. Riset Operasi, Suatu Pengantar, jilid 2. Binarupa Aksara. Jakarta.

Lampiran 1. Sistem antrian pada klinik dr. JHA

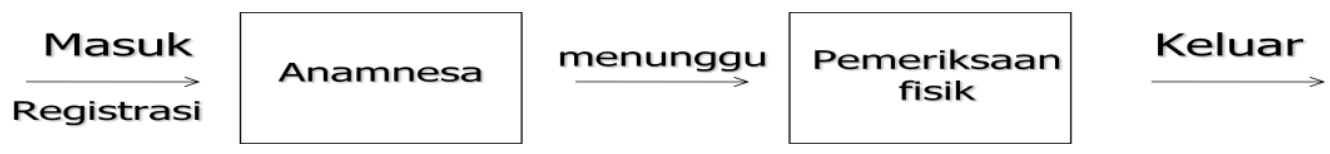

